\title{
Adoptive T cell therapy of cancer
}

\author{
Ton N.M. Schumacher and \\ The Division of Immunology, The Netherlands Cancer Institute, Plesmanlaan 121, 1066 CX, \\ Amsterdam, The Netherlands. t.schumacher@nki.nl \\ Nicholas P. Restifo \\ Clinical Research Center, National Cancer Institute, Room 3-5762, Bethesda, MD, 20892, USA, \\ restifo@nih.gov
}

\begin{abstract}
This edition on Tumor Immunology is focused on the preclinical development and clinical testing of adoptive cell transfer (ACT)-based immunotherapies. The rationale for ACT is strong: it involves the administration of large numbers of highly selected cells with high avidity for tumor antigens. These $\mathrm{T}$ cells can be programmed and activated ex vivo to exhibit antitumor effector functions. This is important because tumor-specific $\mathrm{T}$ cells can be inactivated at early stages of cellular transformation [1]. Furthermore, T cell infusion may be preceded by 'conditioning' of the patient with lymphodepleting chemotherapy or total body irradiation, which enables the diminution of immunosuppressive cell types/ factors followed by the infusion of tumor-specific $\mathrm{T}$ cells [2].
\end{abstract}

Two different strategies for the source of the adoptively transferred $\mathrm{T}$ cells should be distinguished: naturally-occurring $\mathrm{T}$ cells and genetically engineered $\mathrm{T}$ cells. In humans with cancer, naturally-occurring autologous tumor-specific $\mathrm{T}$ cells can only reliably be grown from patients with melanoma. If the desired tumor-reactive $\mathrm{T}$ cell repertoire is normally not present, our task is to engineer such a repertoire [3]. Although limited to the one histology of melanoma, the adoptive transfer of tumor-infiltrating lymphocytes can be highly effective. The second strategy can be more broadly applied and is conceptually similar to the clinical use of recombinant antibodies such as Herceptin and Rituxan that target non-mutated target structures on human tumors. While highly attractive, clinical experiences with genetically engineered $\mathrm{T}$ cells are only starting to emerge.

Within this edition, we have aimed to bring together a number of linked reviews that collectively cover the three major issues that we see in the development of adoptive $\mathrm{T}$ cell therapy: 1). What antigens should be targeted? 2). What are the most effective cells to use? 3). How can ACT-based immunotherapies successfully be implemented in the clinic?

The notion that antigen choice is in our view a significant issue is perhaps surprising in view of the fact that -following a spate of activity in the 80's and 90's - antigen discovery efforts have in large part been abandoned in recent years. However, as discussed by Offringa [4], even though this prior research has revealed the identity of a large number of $T$ cell antigens, in most cases it is unclear whether the targeting of these antigens with high affinity T cells would result in an acceptable toxicity profile. Notably, recent work on the induction of high avidity T cell responses against CEA and p53 in mouse models provides a very clear warning in this regard. In addition, evidence of significant on-target toxicity has also been obtained in a phase I trial

\footnotetext{
Publisher's Disclaimer: This is a PDF file of an unedited manuscript that has been accepted for publication. As a service to our customers we are providing this early version of the manuscript. The manuscript will undergo copyediting, typesetting, and review of the resulting proof before it is published in its final citable form. Please note that during the production process errors may be discovered which could affect the content, and all legal disclaimers that apply to the journal pertain.
} 
by Lamers et al. using receptor-engineered T cells [5]. Collectively these studies argue that there is a strong need for better datasets that can be used to predict the suitability of different antigens for adoptive $\mathrm{T}$ cell therapy. As a second related objective, it will become increasingly important to define which tumor-associated antigens can be considered tumor-rejection antigens, something that will be determined by factors such as the level and heterogeneity of expression and the likelihood of antigen loss.

A subsequent series of reviews focuses on the differentiation state and antigen reactivity of the cells that are utilized for adoptive T cell therapy. A first of these reviews by Berger and colleagues [6] draws upon data obtained from human trials and studies in non-human primates that examine the differentiation state of $\mathrm{T}$ cells used for adoptive cell therapy and the effect of the host environment that these cells encounter upon transfer. A highly informative study by the authors demonstrating that central memory cells rather than effector memory cells should be used as 'starting material' for in vitro expansion processes provides a strong incentive for the development of $\mathrm{T}$ cell isolation strategies that selectively yield those cells [7]. Likewise, the elucidation of the mechanisms through which the administration of lymphodepleting chemotherapy or total body irradiation enhances $\mathrm{T}$ cell persistence should form the starting point for the design of more refined strategies that may potentially achieve the same goal.

With few notable exceptions, adoptive T cell therapy of human cancer has focused on the generation of a tumor-reactive repertoire of $\mathrm{CD} 8^{+} \mathrm{T}$ cells. However, as outlined by Muranski and Restifo [8], there is significant reason to also investigate the potential of adoptive $\mathrm{T}$ cell therapy with $\mathrm{CD} 4^{+} \mathrm{T}$ cells, either as stand-alone therapy or in combination with tumor-specific $\mathrm{CD}^{+}$cells. The reason why work on adoptive $\mathrm{T}$ cell therapy with helper $\mathrm{T}$ cells has lagged behind is mostly practical. Due to the substantially higher diversity of MHC class II products, the incentive to map tumor-associated epitopes has been less, and few well-characterized tumor antigen-reactive receptors are currently available. However, with the first evidence of the potential of $\mathrm{CD}^{+}$cells emerging [9], a growing effort will likely be made in this field. As pointed out by Muranski and Restifo, in these efforts it will be of particular importance to define which polarization state of $\mathrm{CD} 4^{+}$cells should be aimed for.

Reviews by Sadelain and colleagues [10] and Bendle and colleagues [11] focus on the requirements for adoptive cell therapy with $\mathrm{T}$ cells that either carry chimeric antigen receptors (CARs) or T cell receptors (TCRs). The potential value of CAR-engineered T cells that allow MHC-independent recognition of tumor cells was recognized over 15 years ago [12]. However, the inability of first generation CARs to provide a signal for $\mathrm{T}$ cell proliferation formed a significant concern, and - possibly because of this - early clinical experiences with CARmodified $\mathrm{T}$ cells have shown only very modest clinical effects. Notably, the development of second generation CARs that do allow expansion of $\mathrm{T}$ cells triggered through the chimeric receptor in preclinical experiments has led to the design of a series of new phase I clinical trials. These trials will provide an important test of the value of such second generation chimeric antigen receptors in the coming years and will help decide whether at this point in their development CARs do or do not form an attractive alternative over classical TCRs. The review by Bendle and colleagues [11] describes the results coming from a set of mouse studies that have aimed to define optimal conditions for adoptive transfer of TCR-modified T cells. Importantly, some of the models used to define such conditions have specifically focused on the generation of $T$ cell reactivity against self antigens to which the endogenous $T$ cell repertoire is non-responsive, thereby providing a critical test of the value of TCR gene modification to create a new repertoire. Key factors identified in these mouse studies have been the use of expression systems that yield high TCR expression, the use of lymphodepletion rather than vaccination to promote $T$ cell persistence and the generation of $T$ cell grafts that contain a high frequency of gene-modified cells. Future work in this field may assess the effect of gene modifications additional to the introduction of TCR genes on in vivo T cell function. 
Furthermore, an assessment of the role of different helper T cell subsets would seem of interest. Finally, it would seem worthwhile to directly compare the relative value of $\mathrm{T}$ cells modified with either TCR or CAR genes in such murine models.

The final review in this issue by Rosenberg and Dudley [13] describes their extensive clinical experience with adoptive $T$ cell therapy for patients with metastatic melanoma. The work by the NIH Surgery Branch in this field over the past years has provided a very strong impetus for the development of adoptive cell therapy with either tumor-derived T cells or TCRengineered $\mathrm{T}$ cells. In addition, the finding by this group that lymphodepleting chemotherapy or total body irradiation has a strong beneficial effect on the clinical efficacy of ACT forms a striking illustration of how data obtained in clinical trials can form the starting point of preclinical research aimed at elucidating the underlying mechanisms [14].

What can we expect with regard to the future developments of adoptive T cell therapy? In the coming years, the use of more advanced culture protocols will surely enhance the in vivo function of adoptively transferred cells. In addition, a large new series of antigen receptors will be tested in clinical trials. In the longer term, it seems plausible that the engineering of T cell used in clinical trials will become increasingly advanced and we will make three predictions. First, the engineering of $\mathrm{T}$ cells that are insensitive to suppressive influences present within the tumor environment will likely be of value. Second, the use of T cells that do or do not become active based on the input of two or more receptors (i.e. that form logic gates) comprises a conceptually attractive strategy to further enhance the specificity of genetically engineered T cells. Finally, the output generated by signaling through such introduced receptors could potentially be manipulated to enhance the effectiveness against tumor cells that are less sensitive to the physiological mechanisms of T cell-mediated target cell death.

\section{References}

1. Willimsky G, Blankenstein T. Sporadic immunogenic tumours avoid destruction by inducing T-cell tolerance. Nature 2005;437:141-146. [PubMed: 16136144]

2. Dudley ME, Wunderlich JR, Robbins PF, Yang JC, Hwu P, Schwartzentruber DJ, Topalian SL, Sherry R, Restifo NP, Hubicki AM, et al. Cancer regression and autoimmunity in patients after clonal repopulation with antitumor lymphocytes. Science 2002;298:850-854. [PubMed: 12242449]

3. Schumacher TN. T-cell-receptor gene therapy. Nat Rev Immunol 2002;2:512-519. [PubMed: 12094225]

4. Review by Offringa R. Antigen choice in adoptive T cell therapy of cancer. In this issue. Curr Opin Immunol 2009;X:X.

5. Lamers CH, Sleijfer S, Vulto AG, Kruit WH, Kliffen M, Debets R, Gratama JW, Stoter G, Oosterwijk E. Treatment of metastatic renal cell carcinoma with autologous T-lymphocytes genetically retargeted against carbonic anhydrase IX: first clinical experience. J Clin Oncol 2006;24:e20-22. [PubMed: 16648493]

6. Berger C, Turtle CR, Jensen MC, Riddell SR. Adoptive transfer of virus-specific and tumor-specific T cell immunity. Curr Opin Immunol 2009;X:X.

7. Berger C, Jensen MC, Lansdorp PM, Gough M, Elliott C, Riddell SR. Adoptive transfer of effector CD8+ T cells derived from central memory cells establishes persistent $\mathrm{T}$ cell memory in primates. $\mathrm{J}$ Clin Invest 2008;118:294-305. [PubMed: 18060041]

8. Muranski P, Restifo NP. Adoptive immunotherapy of cancer using CD4+ T cells. Curr Opin Immunol 2009;X:X.

9. Hunder NN, Wallen H, Cao J, Hendricks DW, Reilly JZ, Rodmyre R, Jungbluth A, Gnjatic S, Thompson JA, Yee C. Treatment of metastatic melanoma with autologous CD4+ T cells against NYESO-1. N Engl J Med 2008;358:2698-2703. [PubMed: 18565862]

10. Sadelain M, Brentjens R, Riviere I. The promise and potential pitfalls of chimeric antigen receptors for cancer therapy. Curr Opin Immunol 2009;X:X. 
11. Bendle GM, Haanen JB, Schumacher TN. Preclinical development of T cell receptor gene therapy. Curr Opin Immunol 2009;X:X.

12. Eshhar Z, Waks T, Gross G, Schindler DG. Specific activation and targeting of cytotoxic lymphocytes through chimeric single chains consisting of antibody-binding domains and the gamma or zeta subunits of the immunoglobulin and T-cell receptors. Proc Natl Acad Sci U S A 1993;90:720-724. [PubMed: 8421711]

13. Dudley ME, Rosenberg SA. Adoptive Cell Therapy for the Treatment of Patients with Metastatic Melanoma. Curr Opin Immunol 2009;X:X.

14. Gattinoni L, Powell DJ Jr, Rosenberg SA, Restifo NP. Adoptive immunotherapy for cancer: building on success. Nat Rev Immunol 2006;6:383-393. [PubMed: 16622476]

\section{Biographies}

Ton NM Schumacher is Senior Member of The Netherlands Cancer Institute and Professor of Immunotechnology at Leiden University. His laboratory focuses on the development and clinical translation of technologies for adoptive therapy and immunomonitoring.

Nicholas P. Restifo is a Principal Investigator at the National Cancer Institute in Bethesda, Maryland. His laboratory focuses on basic and translational aspects of tumor immunology and adoptive immunotherapy. 